\title{
Functionally Graded Martensitic Stainless Steel
}

\author{
S.Tharaknath. M.Tech ${ }^{1,}$ H. Dineshkumar ${ }^{2}$ G. Purushothaman ${ }^{3}$, \\ C. Kannadhasan ${ }^{4}$, S.Silambarasan ${ }^{5}$ \\ ${ }^{I}$ (Asst professor, Priyadarshini Engineering College/ Anna university, India) \\ 3, 4,5 (Engineering design, Priyadarshini Engineering College/ Anna university, India)
}

\begin{abstract}
Functionally graded materials (FGM) are defined as an anisotropic material whose physical properties vary continuously throughout the volume, either randomly or strategically, to achieve desired characteristics or functionality. The aim of this project is to perform a modal analysis to determine the natural frequencies and mode shapes of a FGM using Finite Element Analysis (FEA). A modal analysis will be performed on isotropic cases with FEA and compared its known theoretical solution. FGMs are then chosen in increasing complexity and modal analysis is performed on each case. These analyses are compared to the natural frequencies of the constituent materials computed in the isotropic cases. The natural frequencies of the FGMs are Compared known solutions in literature, if they exist or compared to analytic models for computing FGMs. In all cases of modal analysis, the FEA are validated by mesh extension trials and convergence tests.
\end{abstract}

Keywords: natural frequency of the FGMs, modal analysis

\section{Introduction}

FGM are typically designed for a specific function or application. Many times they are manufactured to achieve good strength to weight ratios, good thermal or electrical conductivity, or various other material advantages. FGMs differ from traditional composites in that their material properties vary continuously, where the composite changes at each laminate interface. FGMs accomplish this by gradually changing the volume fraction of the materials which make up the FGM.

\section{Functional Graded Material}

$>$ FGM Functionally Graded Material

> MA1 Martensitic Stainless Steel Alloy with 13 wt.\% Chromium and 0.13 wt.\% Carbon

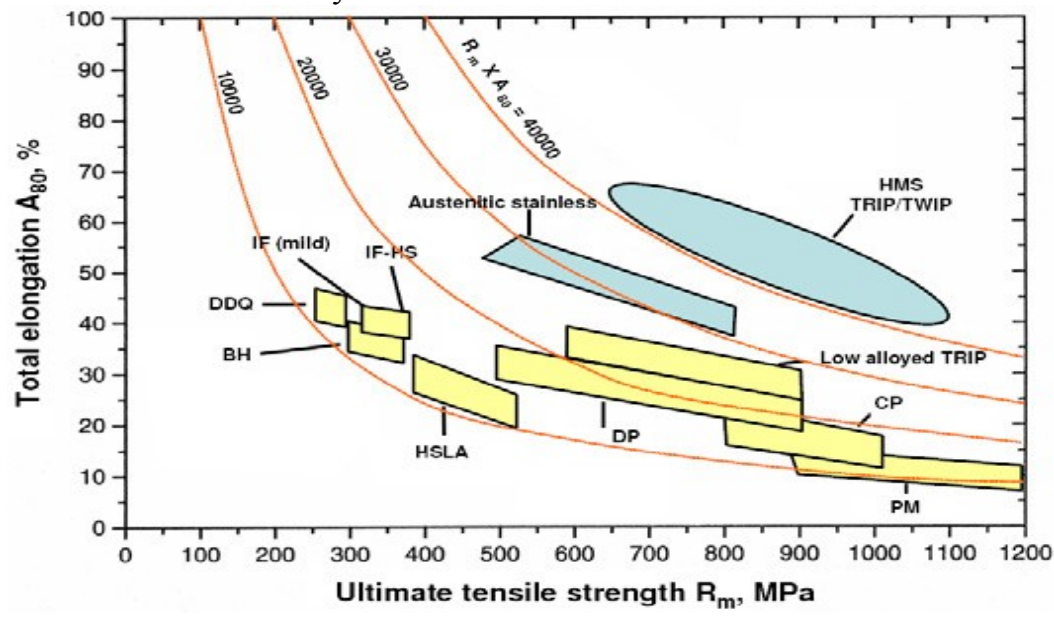

FIGURE 1- "Banana Chart" Of Steel Ductility Versus Strength

To combat this lack of ductility in martensitic steels partially decarburizing the material has been proposed by Chehab et al. [4]. This has been done in other steels, particularly in spheroidite and pearlite [5]. What makes stainless steel different from other grades of steel is the passivated chromia layer that forms on its surface. This is the reason why stainless steel is stainless but there is also a possibility that the protective layer could inhibit diffusion of carbon when gaseous decarburization is used. Fortunately, Cao [6] disproved this. Cao found "that at low temperatures $\mathrm{Cr} 2 \mathrm{O} 3$ constitutes a barrier for carbon diffusion into the specimens" (Cao, 2003 pg. 65). However, at higher temperatures diffusion kinetics are so fast that this effect of diffusion inhibition is reduced. 

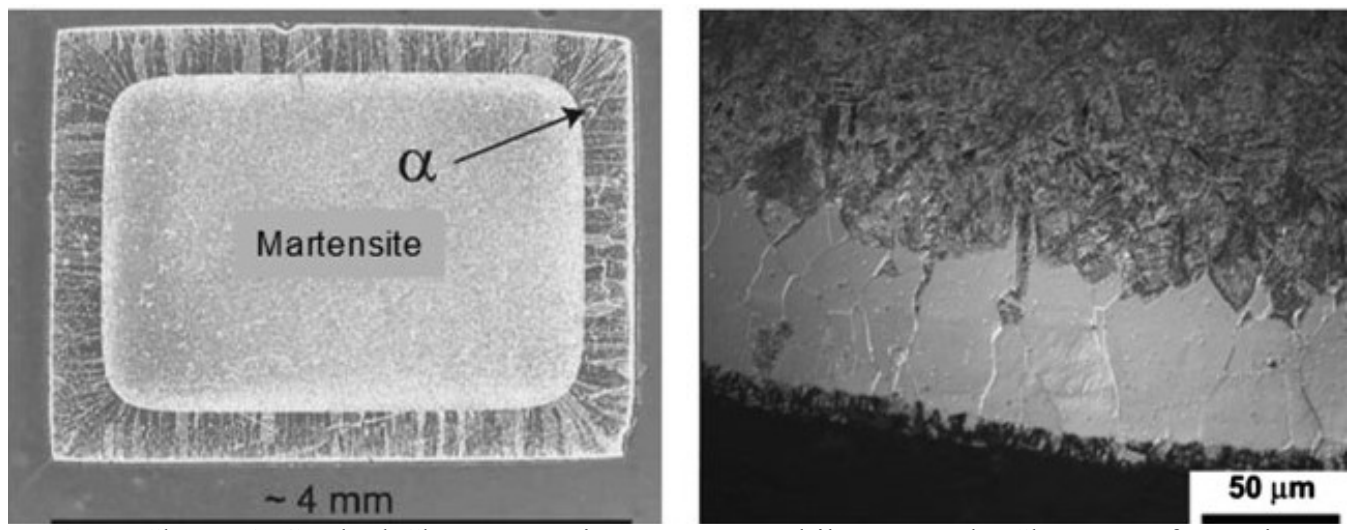

FIGURE 2 (A) Shows A Gradual Change In Microstructure While (B) Is The Sharp Interface Microstructure

Composite materials of this type can undergo two different types of failure modes, necking and fracture [4]. The necking failure mode cannot happen at only one part of the composite, as necking is a global phenomenon. Therefore, when dealing with necking as a failure mode, one must consider the bulk stress and work hardening rate of the material. Fracture on the other hand is different. Different parts of the material will have different stress concentrators or in the case of graded materials, different properties with different KIC values. Therefore, fracture can initiate at the surface or in the core depending on impurities or cracks.

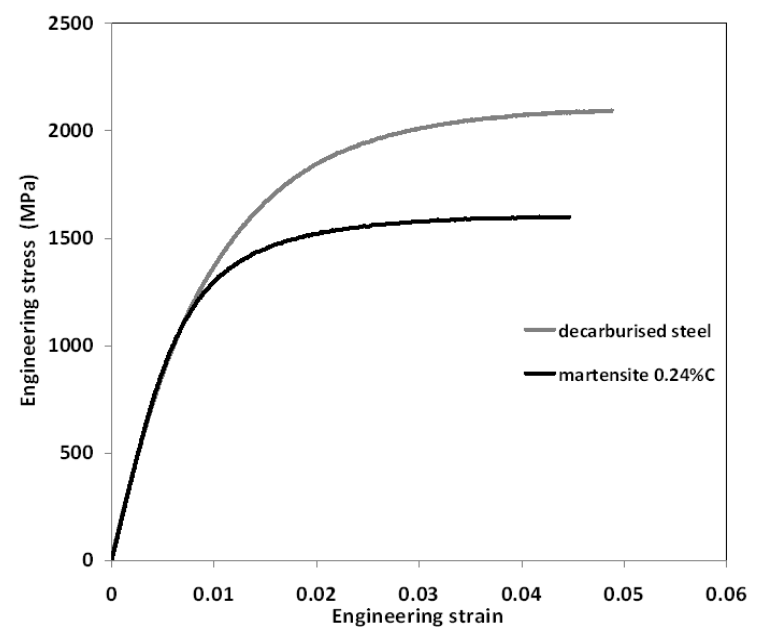

FIGURE 3- Engineering Stress-Strain Curve Comparing A Martensitic Steel And Decarburized Steel [8]

Charpy impact testing was carried out to determine how graded stainless steels behave under very high strain rates and assess their fast fracture properties. The MA1 grade showed the greatest improvement in impact tests between the homogeneous and graded samples in the air quenched and oil quenched. This is because the graded samples had a layer of tough material on the surface around the notch. This allowed for more energy absorption. Decarburization is also shown in the micrographs of the fracture surfaces. The core showed inter granular fracture whereas the edge has cup and cone structure, indicative of ductile fracture. There is also a large difference between oil quenched and air quenched samples, irrespective of whether they had been decarburized or not. This may be due to the fact that air quenching produces a material with lower internal stress than oil quenching, which would allow for more energy absorption. Another reason is the amount of brittle or the amount of tough phase present on the surface due to the quenching rate. Of course the contrast between oil and air quenching is magnified when the homogeneous and decarburized samples are compared, with the greater difference due to decarburization coming in the air quenched samples than in the oil quenched samples. 


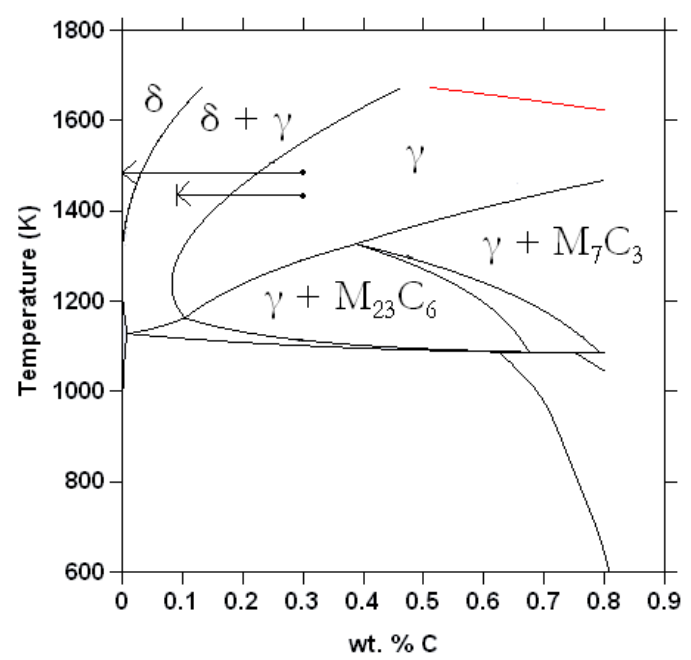

FIGURE 4- Phase Diagram Of The Balance Fe-12.33\%Cr-C System Using The Phase

It can be seen that two main resulting micro structural profiles will be apparent. The first profile is a layer of ferrite at the surface of the steel, which does not transform upon quenching and the core is austenitic which transforms to martensite upon quenching. This can be achieved by decarburizing a relatively low carbon content bulk material to $0 \% \mathrm{C}$, which is in the ferrite region. This results in a ferritc surface and martensitic core. The second is a smooth transition of phases from the core to the surface of the material. This can be obtained by decarburizing a higher bulk carbon content sample to intermediate carbon contents at a high temperature. This places the material, depending on the starting carbon content in one of two regions, ferrite and austenite or just pure austenite. Upon quenching the amount of ferrite in the material will decrease from the surface to the centre and the amount of martensite will gradually increase until it is all martensite. This results in a continuous microstructure with no sudden change from ferrite to martensite.
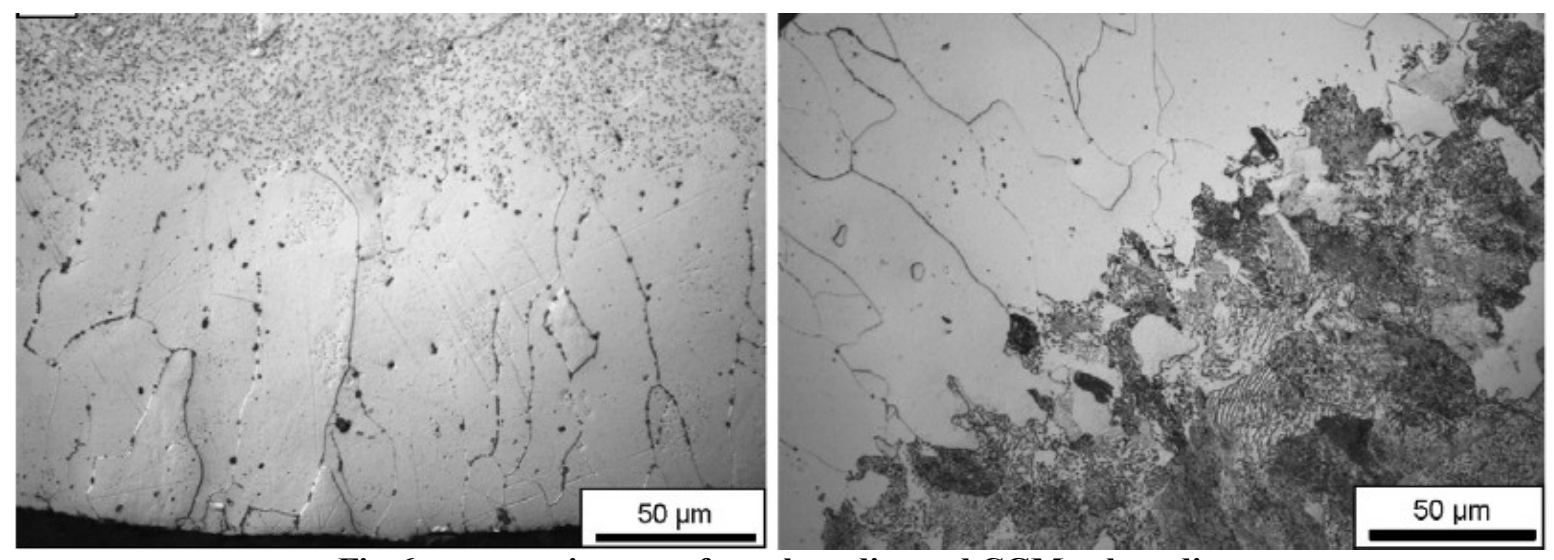

Fig-6stress-strain curve for spherodite and CGM spherodite

\begin{tabular}{|c|c|c|}
\hline Annealing parameters & Vacuum furnace on[torr] & Vacuum furnace off[torr] \\
\hline $530 \mathrm{c}$ & 3.10 & 3.3 \\
\hline $430 \mathrm{c}$ & 6.10 & 3.10 \\
\hline
\end{tabular}

Table-1 Annealing parameters

\begin{tabular}{|c|c|c|c|c|}
\hline Sample & Yield stress & Lueders pllateav & Ultimate stress & Strain at fracture \\
\hline 1 & 133 & Yes & 254 & 0.9 \\
\hline 1 & 147.6 & yes & 279.6 & 0.82 \\
\hline
\end{tabular}

Table-2 Tensile stress

\section{Conclusion}

\section{Sharp Interface}

The first results presented from the model are for sharp interface profile. As can be seen from the optimal martensite volume fraction occurs at around 0.9 , when necking and fracture are both considered. At 0.9 martensite volume fraction, the stress and absorbed energy are both maximized, where as the strain is not at the 
maximum. In fact, the strain at a volume fraction of 0.9 is $60 \%$ smaller than if the sample was $100 \%$ ferrite. This makes sense because in order to maximize ductility, the amount of ferrite would have to be maximized. Having a maximum stress value with $90 \%$ martensite is reasonable because martensite is what gives the material its strength. However, if it were any higher the brittleness of the phase would not be able to accommodate the high stress in the material induced from the surface or internal cracks present in the material. If the \% martensite were any lower, the amount of ferrite in the material would decrease its strength but increase its ductility. Maximizing the strain a material can handle requires using as much of the most ductile phase as possible. In this case ferrite is the most ductile, so having a material that is all ferrite would maximize this property. This is also confirmed through real world observations Maximizing absorbed energy in a material requires careful control over the amount of each phase that is present in a material. This means a fine balance between stress and strain accommodation must be found in order to absorb the most energy in material. that even though the strain at the volume fraction of martensite that maximizes absorbed energy is $60 \%$ lower than the material can obtain at its optimal fraction for strain, the material is able to absorb high amounts of stress because of the martensite present. the model can predict the volume fraction of martensite that maximizes the absorbed at a given strain, ensuring that the material does not reach critical stress or strain. As an example, a maximum strain of $15 \%$ is desired for a given application. that at a $24 \%$ volume fraction of martensite, the absorbed energy in the material is around $58 \mathrm{MJ} / \mathrm{m} 3$. Anything beyond this strain and the material will fail. insight into the trends of the properties of a material and allow engineers to pick a material with the optimal properties desired for a specific application.

\section{Reference}

[1]. "Fundamentals of Functionally Graded Materials: Processing and Thermomechanical Behaviour of Graded Metals and MetalCeramic Composites", S. Suresh and A. Mortensen;

[2]. "Processing Techniques for Functionally Graded Materials", B.Kieback, A. Neubrand, H.Riedel, Material Science and Engineering A362 (2003) 81-105;

[3]. "Infiltration and physical characteristics of functionally graded alumina/calcium-hexaluminate composites", D.Asmi, I.M. Low, Journal of Material Processing Technology, 118 (2001) 225-230

[4]. "Fundamentals of liquid phase sintering for modern cermets and functionally graded cemented carbonitrides (FGCC)", Limin Chen, Walter Lengauer, Peter Ettmayer, Klaus Dreyer, Hans W. Daub, Dieter Kassel, International Journal of Refractory Metals and Hard Materials 18 (2000) 307-322;

[5]. "Synthesis of functionally gradient NiCr-A1/MgO-ZrO2 coating by plasma spray technique", S. Eroglu, N.C.Birla, M.Demirci, T. Baykara, Journal of Material Science Letters 12 (1993), 1099-1102; 